Article

\title{
Antitumor Effect and Induced Immune Response Following Exposure of Hexaminolevulinate and Blue Light in Combination with Checkpoint Inhibitor in an Orthotopic Model of Rat Bladder Cancer
}

\author{
Laureline Lamy ${ }^{1,2}$, Jacques Thomas ${ }^{3}$, Agnès Leroux ${ }^{3}$, Jean-François Bisson ${ }^{4}$, Kari Myren ${ }^{5,+}$, Aslak Godal ${ }^{5, \ddagger}$, \\ Gry Stensrud ${ }^{5, \S}$ and Lina Bezdetnaya ${ }^{1,2, *}$
}

1 Centre de Recherche en Automatique de Nancy, Centre National de la Recherche Scientifique, UMR 7039, Université de Lorraine, Campus Sciences, Boulevard des Aiguillette, 54506 Vandoeuvre-lès-Nancy, France; la.lamy@nancy.unicancer.fr

2 Research Department, Institut de Cancérologie de Lorraine, 6 Avenue de Bourgogne, 54519 Vandoeuvre-lès-Nancy, France

3 Service de Biopathologie, Institut de Cancérologie de Lorraine, 54506 Vandoeuvre-Lès-Nancy, France; j.thomas@nancy.unicancer.fr (J.T.); a.leroux@nancy.unicancer.fr (A.L.)

4 ETAP-Lab., 13 Rue du Bois de la Champelle, 54500 Vandoeuvre-les-Nancy, France; jfbisson@etap-lab.com

5 Photocure ASA, Hoffsveien 4, 0275 Oslo, Norway; myren@oncoinvent.com (K.M.); asgodal@online.no (A.G.); gry.stensrud@lytixbiopharma.com (G.S.)

* Correspondence: 1.bolotine@nancy.unicancer.fr

check for updates

Citation: Lamy, L.; Thomas, J.; Leroux, A.; Bisson, J.-F.; Myren, K.; Godal, A.; Stensrud, G.; Bezdetnaya, L. Antitumor Effect and Induced Immune Response Following Exposure of Hexaminolevulinate and Blue Light in Combination with Checkpoint Inhibitor in an Orthotopic Model of Rat Bladder Cancer. Biomedicines 2022, 10, 548 https://doi.org/10.3390/ biomedicines 10030548

Academic Editor: Stefano Bacci

Received: 17 January 2022

Accepted: 22 February 2022

Published: 25 February 2022

Publisher's Note: MDPI stays neutral with regard to jurisdictional claims in published maps and institutional affiliations.

Copyright: (C) 2022 by the authors. Licensee MDPI, Basel, Switzerland. This article is an open access article distributed under the terms and conditions of the Creative Commons Attribution (CC BY) license (https:// creativecommons.org/licenses/by/ $4.0 /)$.
+ Current employment: Oncoinvent AS, Gullhaugveien 7, 0484 Oslo, Norway.

$\ddagger$ Deceased in September 2021.

$\S$ Current employment: Lytix Biopharma, Sandakerveien 138, 0484 Oslo, Norway.

\begin{abstract}
Previous studies have found that use of hexaminolevulinate (HAL) and blue light cystoscopy (BLC) during treatment of bladder cancer had a positive impact on overall survival after later cystectomy, indicating a potential treatment effect beyond improved diagnostic accuracy. The aim of our study was to determine whether HAL and BL mimicking clinically relevant doses in an orthotopic rat model could have therapeutic effect by inducing modulation of a tumor-specific immune response. We also assessed whether administration with a checkpoint inhibitor could potentiate any effects observed. Rats were subjected to HAL BL alone and in combination with anti-PD-L1 and assessed for anti-tumor effects and effects on immune markers. Positive anti-tumor effect was observed in $63 \%$ and $31 \%$ of rats after, respectively, 12 and 30 days after the procedure, together with a localization effect of CD3+ and CD8+ cells after 30 days. Anti-tumor effect at 30 days increases from $31 \%$ up to $38 \%$ when combined with intravesical anti-PD-L1. In conclusion, our study demonstrated treatment effects with indications of systemic immune activation at diagnostic doses of HAL and blue light. The observed treatment effect seemed to be enhanced when used in combination with intravesically administrated immune checkpoint inhibitor.
\end{abstract}

Keywords: bladder cancer; Hexvix ${ }^{\circledR}$; photodiagnosis; PDT; immune checkpoints

\section{Introduction}

Urothelial carcinoma is the fifth most prevalent cancer worldwide, where non-muscleinvasive bladder cancer (NMIBC) constitutes $75 \%$ of primary diagnosis [1]. NMIBC is characterized by frequent recurrences and progression to muscle-invasive bladder cancer within 24 months after treatment with transurethral resection of bladder tumor (TURBT) followed by intravesical bacillus Calmette-Guérin (BCG) instillation [2].

Use of the photosensitizer hexaminolevulinate (HAL, Hexvix ${ }^{\circledR}$ ) and blue light cystoscopy $\left(\mathrm{BLC}^{\circledR}\right)$ has been introduced to increase detection of tumors during diagnosis and surgical treatment of bladder cancer [3]. HAL induces preferential accumulation of 
intracellular protoporphyrin IX (PpIX) in neoplastic tissue. Illumination with blue light (BL; 380-440 nm) produces a clearly demarcated red fluorescence from malignant tissue. Increased detection leads to more complete tumor resection, resulting in improved short and sustained long-term recurrence rates [4,5]. BLC with HAL is recognized and recommended across international and national guidelines [6,7].

Whereas photodynamic diagnosis (PDD) is a diagnostic modality, photodynamic therapy (PDT) is a promising technology in the treatment of various cancer types. PDT combines the administration of a photosensitizer with the illumination of light of specific wavelength to generate cytotoxic singlet oxygen. PDT destroys tumor cells via direct cell destruction and indirectly via vascular shutdown and induction of acute local inflammatory response resulting in immune system activation [8-12]. HAL-mediated PDT with WL was earlier tested with curative purpose in patients with urothelial carcinoma after TUR and demonstrated efficacy of the treatment without major side effects [13]. Intriguingly, two studies have demonstrated positive impact on patient outcomes after cystectomy in patients who had undergone BLC prior to their cystectomy compared to WL-TURB, indicating an additional effect of BLC beyond pure detection $[14,15]$. Both overall survival and cancerspecific survival were significantly higher in the BLC group, and prior BLC with HAL was found to be an independent predictor of survival after radical cystectomy [15].

A promising new age of immunotherapy has arrived in the form of checkpoint inhibition [16]. Tumor cells can escape immune surveillance by upregulating PD-L1/PD-1 expression in cells of tumor microenvironment. The anti-PD-1 and anti-PD-L1 antibodies bind, respectively, to PD-1 on T cells and PD-L1 on cancer cells preventing the interaction of PD-1 and PD-L1, thus reactivating the anti-tumor immune response of cytotoxic T cells [17]. For bladder cancer treatment, five such drugs have been approved by the FDA for use in different settings, including pembrolizumab for BCG-unresponsive high-risk NMIBC $[18,19]$. Immune checkpoint inhibitors have demonstrated a higher benefit in heavy CD8+ infiltrated tumors and in tumors with high tumor mutational burden [19]. The role of checkpoint inhibition in NMIBC has been summarized by Hahn and coworkers [20].

Several studies on the combined effect of PDT with photosensitizers and immune checkpoint inhibition in preclinical models aiming to improve the therapeutic efficiency have been reported [21]. Enhanced anti-tumor efficacy was demonstrated in murine tumor models including breast, subcutaneous, melanoma, renal cell carcinoma, and colon through a combined action of checkpoint inhibitors and PDT. The local treatment of tumor together with the systemic administration of checkpoint inhibitors primed an immune response resulting in increased infiltration of activated CD8+ T cells in the primary tumor, but also in secondary tumors/metastases indicating an abscopal effect. Moreover, an immunological memory effect was developed as PDT-treated tumor-free mice were protected against developing new tumors when re-challenged [21-25].

We hypothesized that the positive impact on patient outcomes in patients who had undergone BLC prior to cystectomy could be caused by a direct anti-tumor effect and/or activation of the immune system as seen with PDT. Therefore, as a proof-of principle study for future translation study, we investigated whether intravesical administration of HAL followed by a diagnostic blue light illumination regime (PDD) could have an antitumor and immune modulating effects, as well as increasing susceptibility to PD-1/PD-L1 pathway inhibition in a preclinical model. Rats were therefore treated with HAL and BL in an orthotopic model of bladder cancer and subjected to histopathological analysis and assessment of immune markers. Co-administration of HAL BL with a checkpoint inhibitor was further tested in this model aiming to assess for potentiation of anti-tumor effects.

\section{Materials and Methods}

\subsection{Tumor Cells Culture}

The rat bladder TCC cell line AY-27 has been established as a primary bladder tumor in Fischer 344 rats by feeding the rats with N-(4-[5-nitro-2-furyl]-2-thiazolyl) formamide. The bladder tumor cells were cultured in vitro as a monolayer at $37{ }^{\circ} \mathrm{C}$ in a humidified $5 \% \mathrm{CO}_{2}$ 
and 95\% air atmosphere in RPMI 1640 culture media (Sigma, Saint-Quentin Fallavier, France) complemented with 9\% FCS, 1\% L-glutamine and 1\% antibiotic/antimycotic solution. Cells were passaged when nearly confluent. The cell culture medium and other culture ingredients and PBS were obtained from Sigma (France).

\subsection{Orthotopic Tumor Model}

Nine-week-old female Fischer rats (Charles River Laboratories, Chatillon-sur-Chalronne France) weighing 140-165 g were housed in groups of 4 rats per cage in a room with 12-h inverted light/dark cycle and controlled temperature $\left(22 \pm 2{ }^{\circ} \mathrm{C}\right)$. Animal care protocols were used in accordance with the guidelines of the European Communities Council Directive on the approximation of laws, regulations, and administrative provisions of the Member States regarding the protection of animals used for scientific purposes, the National Institutes of Health Guide for the care and use of laboratory animals, and the ASAB Ethical Committee. The studies received approval from the French Ministry of Higher Education and Research (agreements no. APAFIS\#14510 on 9 July 2018, and no. APAFIS\#23597 on 3 March 2020). Animal supervision was performed daily. All efforts were made to prevent animal suffering.

Tumors were induced as initially described by Xiao et al. [26]. Briefly, animals were anaesthetized with an intraperitoneal injection (i.p.) of ketamine/xylazine mixture $\left(54 / 6 \mathrm{mg} \cdot \mathrm{kg}^{-1}\right)$ to maintain $\sim 1.5 \mathrm{~h}$ of anesthesia and fixed on animal boards kept at $37^{\circ} \mathrm{C}$. The anesthesia was completed by i.p. injection of $0.01 \mathrm{mg} / \mathrm{kg}$ opioid-based buprenorphine. After urethral catheterization of the bladder with a 16-gauge plastic intravenous cannula, the bladder urothelium was first conditioned with $0.5 \mathrm{~mL} \mathrm{HCl}(0.1 \mathrm{~N})$ for $15 \mathrm{~s}$, neutralized with $0.5 \mathrm{~mL}(0.1 \mathrm{~N}) \mathrm{NaOH}$ for $15 \mathrm{~s}$, and immediately washed several times with sterile physiological serum. Then, a suspension of AY-27 cells (106 cells) in $0.5 \mathrm{~mL}$ of medium was instilled into the bladder via the catheter for $1 \mathrm{~h}$.

\subsection{Hexylaminolevulinate Preparation and Administration}

Hexylaminolevulinate (HAL HCl (Mw 251)) was kindly provided by Photocure ASA, Oslo, Norway. HAL was dissolved in RPMI medium (without serum) immediately before instillation and $0.5 \mathrm{~mL} 8 \mathrm{mM}$ were instilled intravesically and kept for $1 \mathrm{~h}$. After bladder evacuation, bladders were washed three times with the PBS solution followed by illumination.

\subsection{Illumination of Rat Bladders}

Whole bladder illumination with blue light (BL) was performed at day 5 after tumor cell implantation using a $200 \mathrm{~mW}$ Modulight laser model ML 6500 with excitation wavelength at $405 \mathrm{~nm}$, coupled to fiber with a cylindrical diffuser $(1 \times 5 \mathrm{~mm}$, Medlight placed in a central position in the bladder filled with $0.5 \mathrm{~mL}$ PBS. During illumination the irradiance was fixed at $7 \mathrm{~mW} / \mathrm{cm}^{2}$ and a total light dose was $7.5 \mathrm{~J} / \mathrm{cm}^{2}$. The illumination parameters were selected to mimic the irradiance and light doses used during a clinical blue light cystoscopy. The selected parameters were in the same range as reported by Karl Storz for their D-Light C Photodynamic Diagnosis (PDD) system [27].

\subsection{Combination Therapy}

Mouse PD-L1 monoclonal antibody (clone 10F.9G2; Bio-XCell) was delivered by manufacturer as a liquid stock solution $(7.50 \mathrm{mg} / \mathrm{mL})$ and stored at $4{ }^{\circ} \mathrm{C}$. Immunotherapy was conducted using two administration routes of anti-PD-L1: intravesical (ives) and intraperitoneal (i.p.). Treatment scheme was selected based on prior studies in rodents of combined action of immune checkpoints inhibitors with either radiotherapy or PDT [22,28]. Treatment scheme is presented in Figure 1. 
(a)

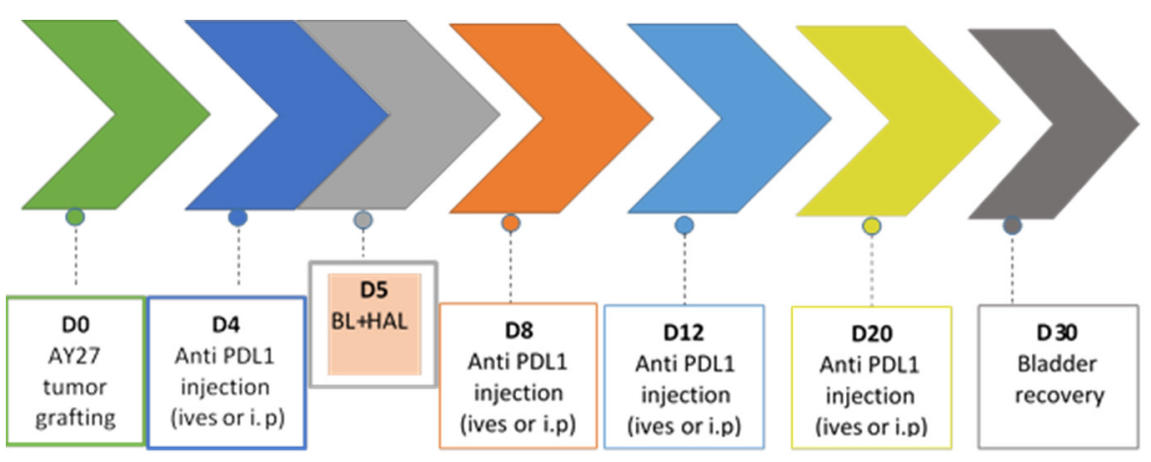

(b)

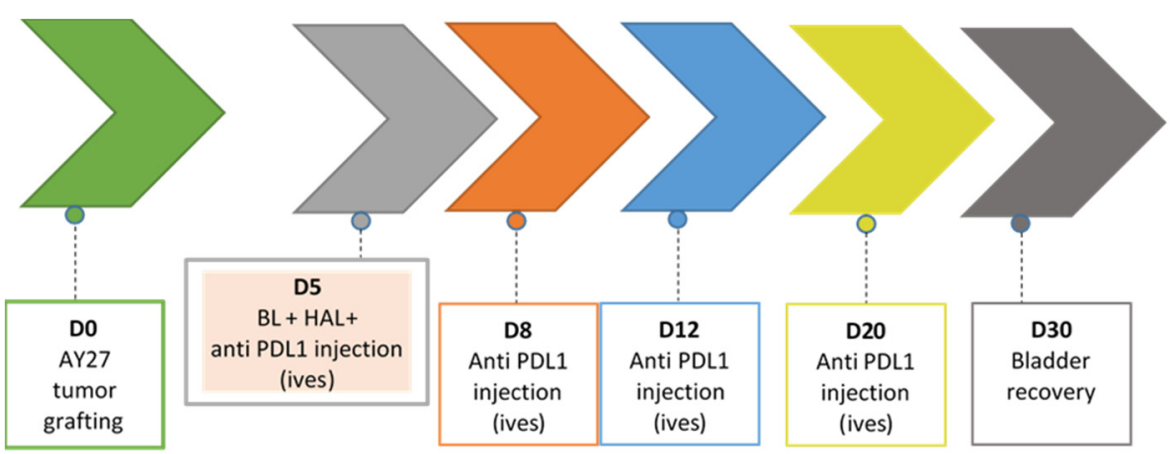

Figure 1. Experimental scheme of HAL BL treatment alone and in combination with anti PDL1 injections. (a) Intraperitoneal (i.p.) and intravesical (ives) administrations; (b) anti PD-L1 coadministration with HAL (same syringe).

\subsubsection{Intraperitoneal Injections (i.p.)}

For i.p. injections, no additional anesthesia was required. Stock PD-L1 solution was diluted in endotoxin-free PBS immediately before use. At each of four PD-L1 injections, rats received $100 \mu \mathrm{L} /$ rat of anti-mouse PD-L1 antibody at the concentration of $2 \mathrm{mg} / \mathrm{mL}$. A treatment dose of $0.2 \mathrm{mg} / \mathrm{rat} /$ injection was selected based on prior published experience [28]. Injections were performed at days 4, 8, 12, and 20 after tumor implantation (Figure 1).

\subsubsection{Intravesical Instillations (ives)}

Instillation was done during $1 \mathrm{~h}$ under ketamine/xylazine anesthesia. At each of four PD-L1 ives instillations, rats received $500 \mu \mathrm{L} /$ rat of antibody at the concentration $7.5 \mathrm{mg} / \mathrm{mL}$. The dose of $3.75 \mathrm{mg} / \mathrm{rat} /$ injection was selected to represent the dose used in clinical settings [29], recalculated for equivalent doses in rats. Two schedules of anti-PD-L1 ives instillations were used: on days $4,8,12$, and 20 or on days $5,8,12$, and 20 after tumor cells implantation. In the second schedule, the first anti-PDL1 instillation (on day 5) was co-administered together with HAL (in one syringe) (Figure 1).

\subsection{Pathological and Immunological Analysis}

The rats were sacrificed by intracardiac overdose of pentobarbital at 7, 12, and 30 days after tumor cell inoculation for pathological and immunological analysis.

\subsubsection{Hematoxylin-Eosin-Safran (HES) Analysis}

Cystectomy specimens were fixed with $4 \%$ formaldehyde before paraffin embedding for about $4 \mathrm{~h}$. Afterwards, the bladders were cut in four parts and placed in cassette. After approximately $48 \mathrm{~h}$ in dehydratation bath, the bladders were paraffined. Two sections $(5 \mu \mathrm{m})$ obtained serially at $0.2 \mathrm{~mm}$ intervals were stained with hematoxylin-Eosin-Safran (automatic methods). 
Therapeutic efficacy in rat bladders was graded into 4 groups (Table 1), based on modified Dworak TGR (tumor regression rate) system [30]. These four groups stand for No Response (NR), Moderate Response (MR), Near Complete Response (near CR) and Complete Response (CR). Typical images corresponding to each of four grades are depicted in Figure 2. Positive anti-tumor effect was considered as a sum of near CR and CR.

Table 1. Tumor response grades (adapted with modification from [30]).

\begin{tabular}{cccc}
\hline $\begin{array}{c}\text { No Response } \\
\text { (NR) }\end{array}$ & $\begin{array}{c}\text { Moderate Response } \\
\text { (MR) }\end{array}$ & $\begin{array}{c}\text { Near Complete } \\
\text { Response (Near CR) }\end{array}$ & $\begin{array}{c}\text { Complete Response } \\
\text { (CR) }\end{array}$ \\
\hline $\begin{array}{c}\text { Rat with strong } \\
\text { muscle-infiltrative } \\
\text { tumor }\end{array}$ & $\begin{array}{c}\text { Rats with few tumor } \\
\text { cells or islets of tumor } \\
\text { cells in several areas }\end{array}$ & $\begin{array}{c}\text { Rats with singular } \\
\text { islet of tumor cells or } \\
\text { very few tumor cells }\end{array}$ & $\begin{array}{c}\text { Absence of tumor } \\
\text { cells }\end{array}$ \\
\hline
\end{tabular}

(a)

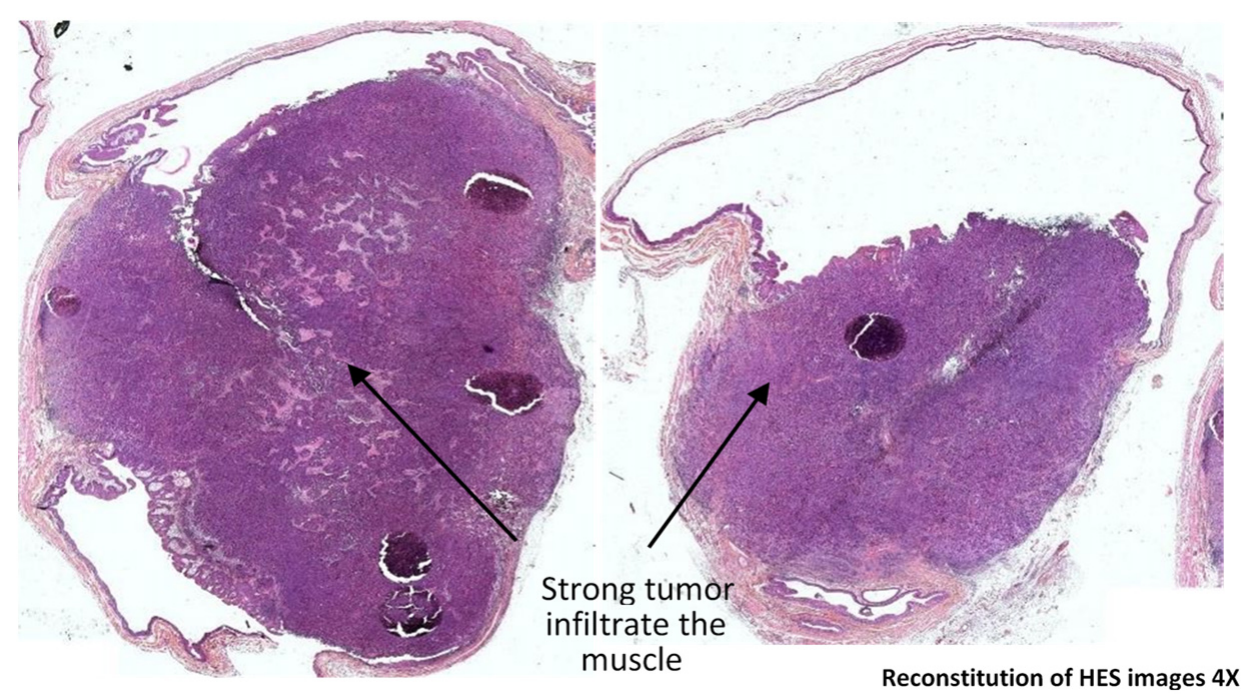

(b)

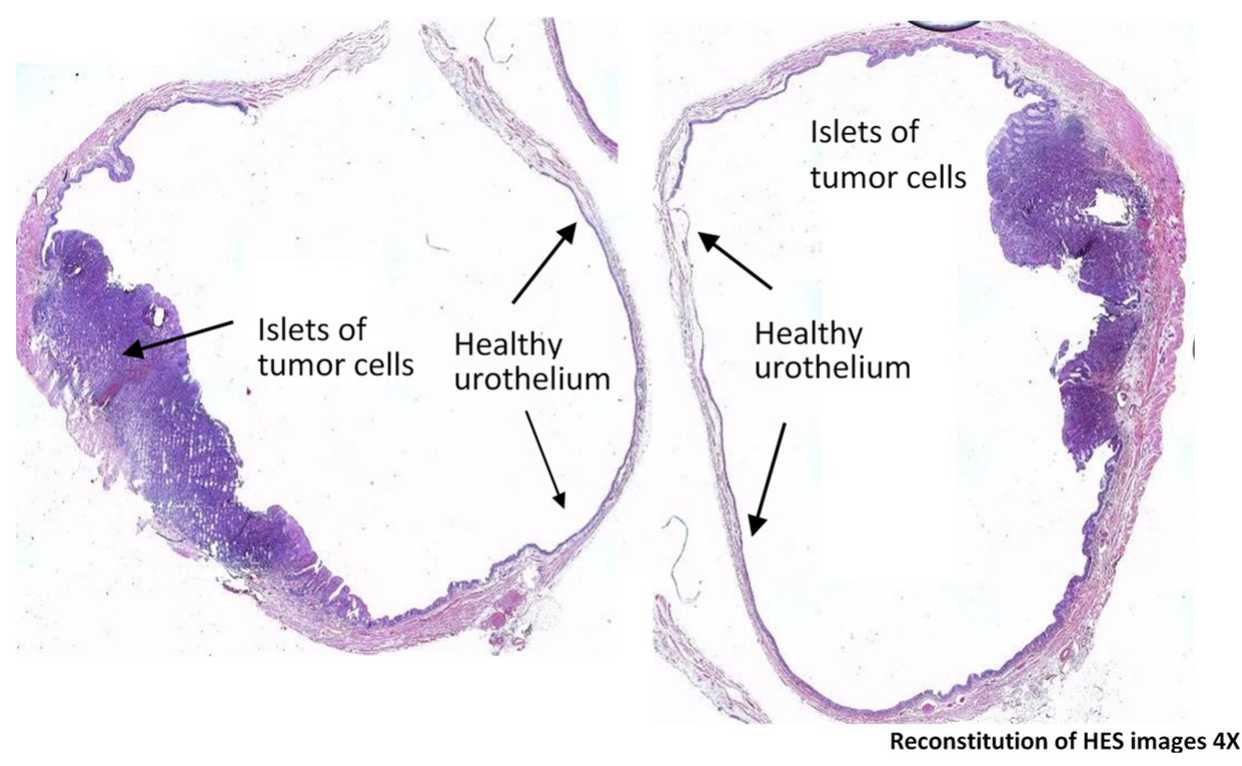

Figure 2. Cont. 
(c)
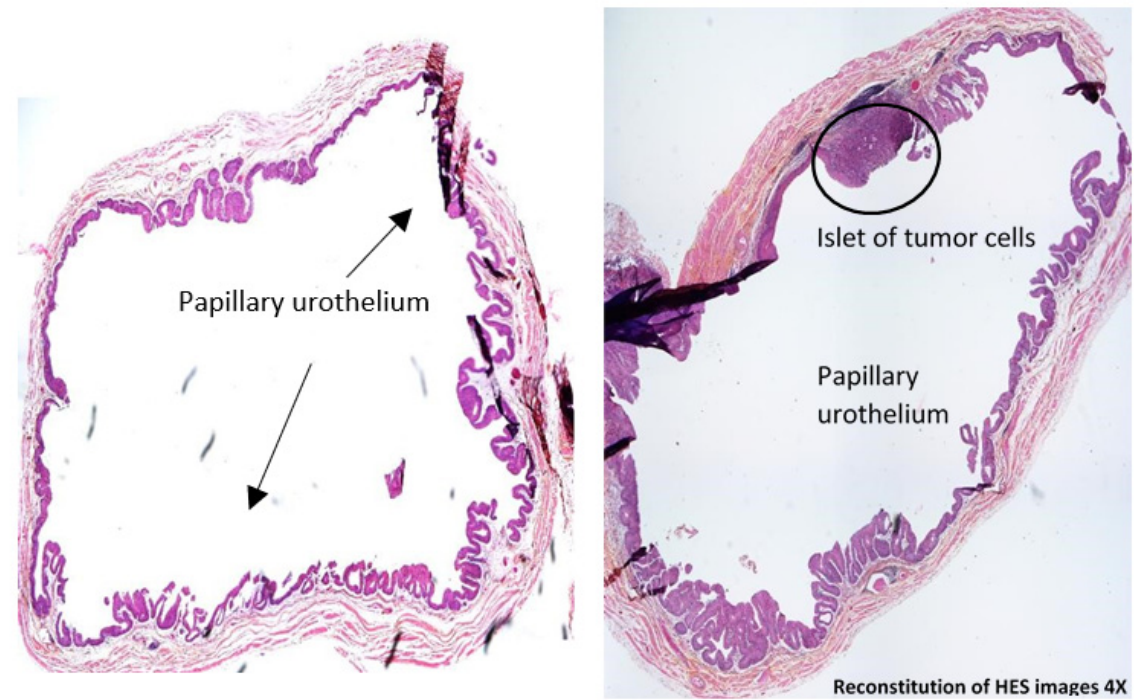

(d)

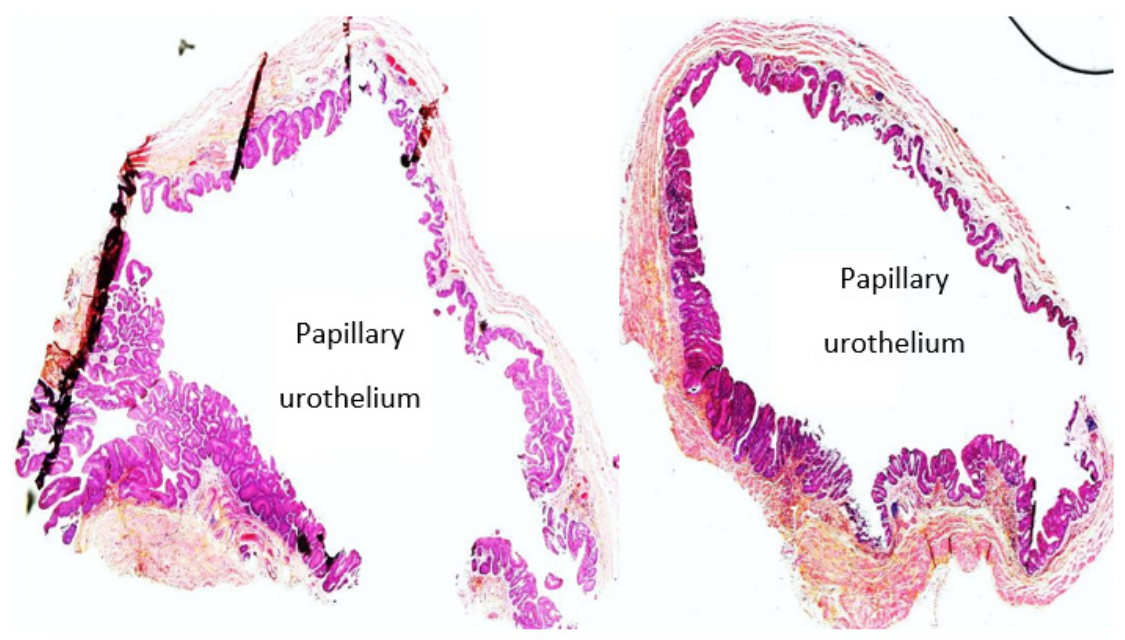

Figure 2. Tumor response grades (adapted with modification from [30]) and bladder tumor typical images corresponding to different response rates. (a) No response (NR): bladders with strong muscleinfiltrative tumor; (b) Moderate response (MR): bladders with few tumor cells or islets of tumor cells in several areas; (c) Near Complete Response (Near CR); (d) Complete Response (CR).

\subsubsection{Assessment of Immune Cells in Tissues}

Inflammatory cells were evaluated by CD3+, CD8+, and CD4+ lymphocytes labeling. $\mathrm{CD} 8+$ and $\mathrm{CD} 4+$ antibodies staining protocol was adapted from a protocol published by Bressenot [31] with slight modifications. CD4+ lymphocytes labeling was performed according to manufacturer recommendations. CD8+ and CD4+ immunohistochemistry (IHC) was carried out on $4 \mu \mathrm{m}$ thick deparaffinized sections in a manual mode. Before staining, the sections were subjected to heat-induced epitope retrieval by incubation in $0.01 \mathrm{M}$ Tris/EDTA solution ( $\mathrm{pH} 8$ ) at $95^{\circ} \mathrm{C}$ for $40 \mathrm{~min}$, followed by $10 \mathrm{~min}$ of cooling. Slices were briefly rinsed with water. The sample on the slide was spotted with dakopen. PBS Tween (0.1 M phosphate buffer, $\mathrm{pH} 7.4,0.1 \%(v / v)$ Tween 20$)$ was added to each spotted sample for $30 \mathrm{~min}$. Endogenous peroxydase activity at each spot was blocked by $5 \mathrm{~min}$ incubation in a $3 \%$ hydrogen peroxide solution in distilled water. Primary antibody was diluted in $1 \%(m / v)$ BSA. With this aim, purified mouse anti-RatCD8a (1: 100 diluted, BD Pharmingen) was incubated at room temperature for $1 \mathrm{~h}$ and mouse anti-rat CD4 W3/25 
(1: 200 diluted, Bio-Rad, Marnes-La- Coquette, France) was incubated at $4{ }^{\circ} \mathrm{C}$ overnight. After that, the slices were washed twice with PBST, each for $10 \mathrm{~min}$ and incubated with secondary antibody, biotinylated goat anti-mouse Ig (multiple adsorption), diluted 1:100 for CD8, and biotinylated donkey anti-mouse IgG, diluted 1:50 for CD4. Secondary antibody remained on the slides for $1 \mathrm{~h}$ at room temperature.

Afterwards, the slices were washed twice with PBST, each for $10 \mathrm{~min}$, followed by incubation with streptavidin-peroxidase (BD Pharmingen) for $30 \mathrm{~min}$ at room temperature. The slices were washed twice with PBST (each for $5 \mathrm{~min}$ ). The Novared TR system (Abcys, Paris, France) was used to detect bound peroxidase (12 min). Nuclear counterstaining was performed with twice diluted Harris hematoxylin $(1 \mathrm{~min})$. At the end of the procedure, the slices were dehydrated in three baths of alcohol (95/100/xylen) and covered by lamellas. IHC CD3 was carried out on $4 \mu \mathrm{m}$ thick deparaffinized sections and further staining was performed with automated immunostainer (BenchMark ULTRA instrument) with flex rabbit polyclonal anti-CD3+ human antibody (Agilent) as primary antibody.

Inflammation was assessed by the expression of CD8+, CD4+ and CD3+ lymphocytes. The ratio of all cell nuclei (Olympus, X40) at several images (4 or 5) achieving totally about 1000 cells to CD8+, CD4+, and CD3+ lymphocytes was calculated.

\subsubsection{PD-L1 Expression in Tumor Cells}

PD-L1 expression was assessed according to manufacturer recommendations. PD-L1 protein detection in paraffin-embedded bladders was determined with mouse monoclonal anti-PD-L1 antibody, Clone 22C3 against PD-L1 (Agilent). Staining was performed by using an automated immunostainer (BenchMark ULTRA instrument). The OptiView DAB IHC Detection Kit (OptiView) is an indirect, biotin-free system for detecting rabbit primary antibody. After this labeling, the slides were visualized by white light microscopy. In the first lieu, assessment at low magnification was performed to identify homogeneity of staining. Afterwards, at high magnification, the areas of interest were analyzed to separate immune PD-L1 positives cells from tumor cells. Finally, PD-L1 positive tumor cells were quantified.

PD-L1 expression was evaluated according to Percentage Staining (PS) of tumor cells used in conventional clinical practice. PS was graded into strong ( $50<$ PD-L1 < 100\%); moderate $(1<$ PD-L1 < 49\%) and weak expression (PD-L1 < 1\%). Typical images corresponding to different levels of PD-L1 expression are indicated in Figure 3.

(a)

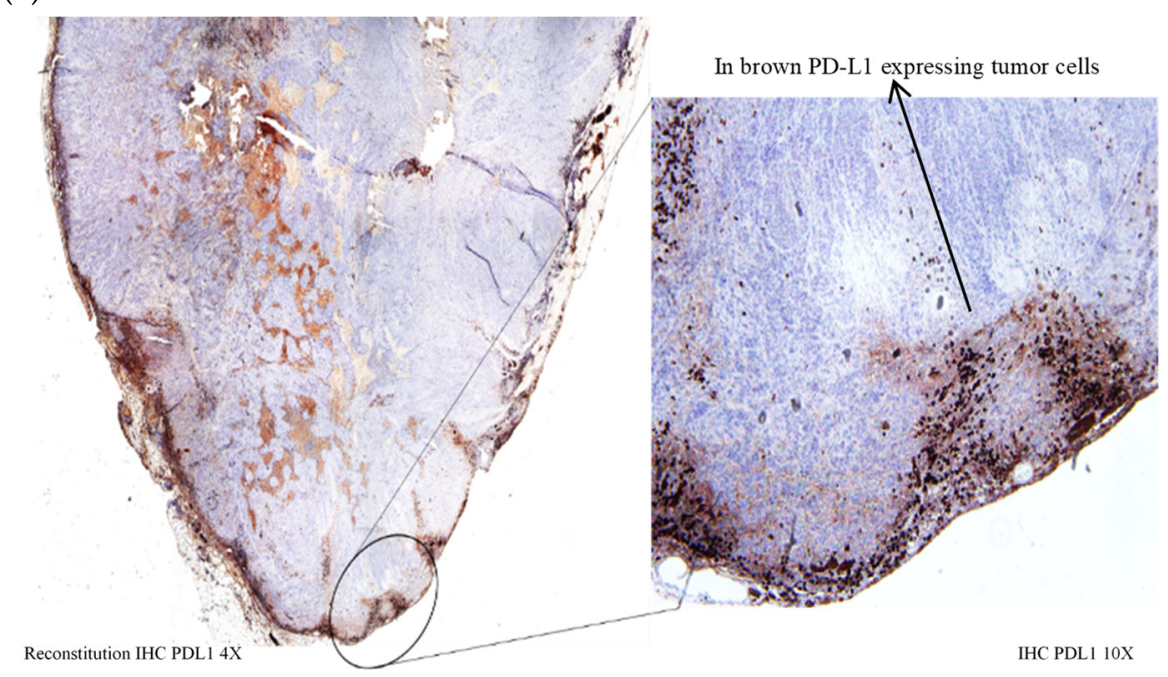

Figure 3. Cont. 
(b)

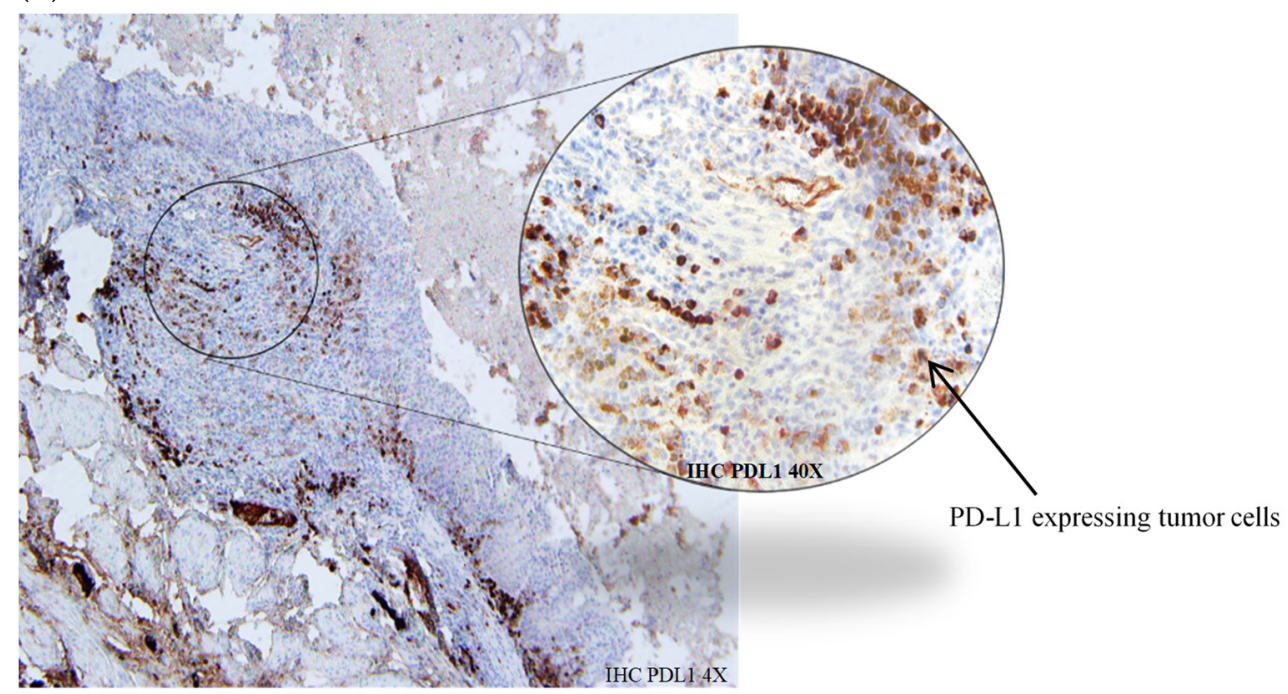

(c)

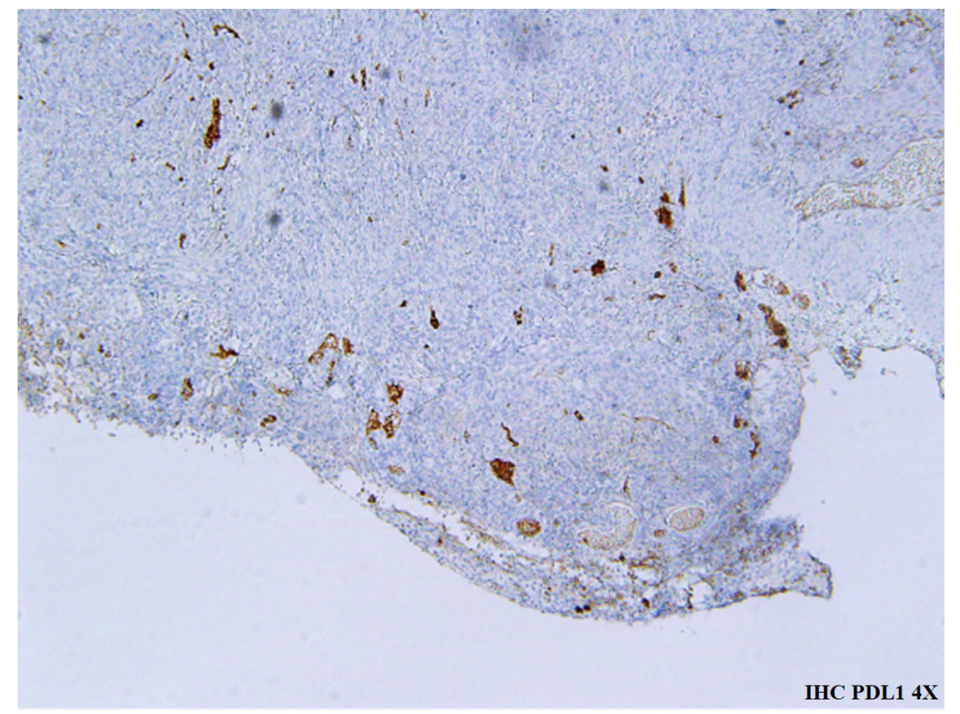

Figure 3. Representative images of PD-L1 staining. (a) Typical image of strong membranous PDL1 expression $(>50 \%)$. Example of bladder sample treated with HAL BL. Membranous PD-L1 expression in tumor cells $(10 \times)$. Photo captured at 12 days post-grafting; (b) typical image of moderate membranous PD-L1 expression $(1<$ PD-L1 < 49\%). Example of bladder sample treated with BL. Membranous PD-L1 expression in tumor cells $(\times 4)$. Photo captured at 30 days post-grafting; (c) typical image of weak membranous PD-L1 expression $(<1 \%)$. Example of bladder sample treated with HAL BL $(\times 4)$. Photo captured at 30 days post-grafting.

\subsection{Statistical Analysis}

The overall number of animals used in this study was 85 . The number of rats differed in each group. For the HES-assessed anti-tumor effect, the numbers of rats in each group were between 6 and 13. For the IHC-assessed PD-L1 expression, the numbers of rats in each group were from 4 to 12 .

Expression of $\mathrm{T}$ lymphocytes is presented as mean $\pm \mathrm{SEM}$; comparison between groups was performed using non-parametric Mann-Whitney $\mathrm{U}$ test. $p$ values $<0.05$ were considered statistically significant.

The correlation between variables and responses was determined by partial least squares regression. The significant main, interaction, and squared terms were found by the backward selection procedure removing one-by-one of the most insignificant terms until 
only significant terms remained $(p<0.05)$. The statistical calculations were performed by the statistical software Modde Pro version 12.0.1, Sartorius Stedim data analytics AB.

\section{Results}

\subsection{HAL-PDD-Mediated Therapeutic Effect in AY27 Orthotopic Bladder Tumors}

We studied the therapeutic effect of HAL and BL illumination at different time points after tumor cell inoculation. Intravesical instillation of HAL and BL illumination was performed five days after tumor grafting. A significant positive therapeutic outcome $(63 \%$; $p<0.05)$ was demonstrated when the rats subjected to HAL BL were assessed 12 days after tumor grafting $(n=8)$ (Table 2). Five rats were either tumor-free $(C R)$ or with few tumor cells (Near CR), while two rats responded moderately (MR). In the last case, we observed a tumor confined to bladder wall but without entire wall invasion. In one rat the treatment was ineffective (NR) (Table 2).

Table 2. HES assessed therapeutic efficacy in rat bladders at 7, 12, and 30 days after tumor inoculation in control and experimental groups.

\begin{tabular}{|c|c|c|c|c|c|c|c|}
\hline \multirow{3}{*}{$\begin{array}{c}\text { Time after Grafting } \\
\text { (d) }\end{array}$} & \multirow{3}{*}{$\begin{array}{c}\text { Treatments } \\
\text { HAL BL }(n=8)\end{array}$} & \multicolumn{6}{|c|}{ Tumor Response Grades } \\
\hline & & \multirow{2}{*}{$\begin{array}{l}\text { NR } \\
1 / 8\end{array}$} & \multirow{2}{*}{$\begin{array}{c}\text { MR } \\
2 / 8\end{array}$} & \multirow{2}{*}{$\begin{array}{c}\text { Near CR } \\
3 / 8 \\
\end{array}$} & \multirow{2}{*}{$\begin{array}{l}\text { CR } \\
2 / 8\end{array}$} & \multicolumn{2}{|c|}{ Near CR + CR } \\
\hline & & & & & & $5 / 8$ & $63 \%$ \\
\hline \multirow{3}{*}{30} & CTR ND NL $(n=12)$ & $12 / 12$ & $0 / 12$ & $0 / 12$ & $0 / 12$ & $0 / 12$ & $0 \%$ \\
\hline & CTR BL $(\mathrm{n}=6)$ & $6 / 6$ & $0 / 6$ & $0 / 6$ & $0 / 6$ & $0 / 6$ & $0 \%$ \\
\hline & HAL BL $(\mathrm{n}=13)$ & $8 / 13$ & $1 / 13$ & $0 / 13$ & $4 / 13$ & $4 / 13$ & $31 \%$ \\
\hline
\end{tabular}

The positive therapeutic outcome was not sustained in rats sacrificed 30 days postgrafting where the beneficial effect was significantly reduced to $31 \%(\mathrm{n}=13 ; p<0.05)$. After 30 days, four out of 13 rats were tumor-free (CR), one rat responded moderately (MR), but 8 out of 13 bladders demonstrated strong muscle-infiltrative tumors (NR) (Table 2). Two control groups were also assessed 30 days after tumor grafting. In the untreated control tumor group (CTR ND NL; $\mathrm{n}=12$ ) HES demonstrated muscle invasive tumors in the chorion in all rats (Table 2). In control rats subjected to BL illumination only (CTR BL; $\mathrm{n}=6$ ), the bladders of all six rats were heavily invaded with tumor (Table 2). All rats in all treatment group survived without any visible sign of suffering.

\subsection{Assessment of Immunological Markers}

In all treated groups we observed a strong inflammation, and therefore in the next step we assessed the recruitment of lymphocytes. The CD3+ inflammatory marker and two subsets of T cells, namely, CD4+ T helper cells and CD8+ cytotoxic T lymphocytes were quantified and their localization was assessed in extracted tumors at different times after tumor grafting.

Expression of CD3+ in untreated control tumors (CTR ND NL) at 12 days post grafting was $17 \%$ (data not shown) and increased significantly to $29 \%$ at 30 days post tumor grafting $(p<0.01)$ (Figure 4). This increase in CD3+ expression in untreated tumors confirms a chronic inflammatory status inherent to tumor presence. CD3+ expression in rat bladders subjected to HAL BL was significantly lower $(19 \% ; p<0.05)$ than that in non-treated group (CTR ND NL) but not different from the control BL group (23\%) (Figure 4).

CD8+ expression was not significantly different between tested groups 30 days after tumor grafting and varied between $18 \%$ and $21 \%$ (data not shown). The expression of CD4+ was overall lower than that of CD8+ and varied between $7 \%$ and $11 \%$ but was not significantly different between tested groups $(p>0.1)$ (data not shown). 


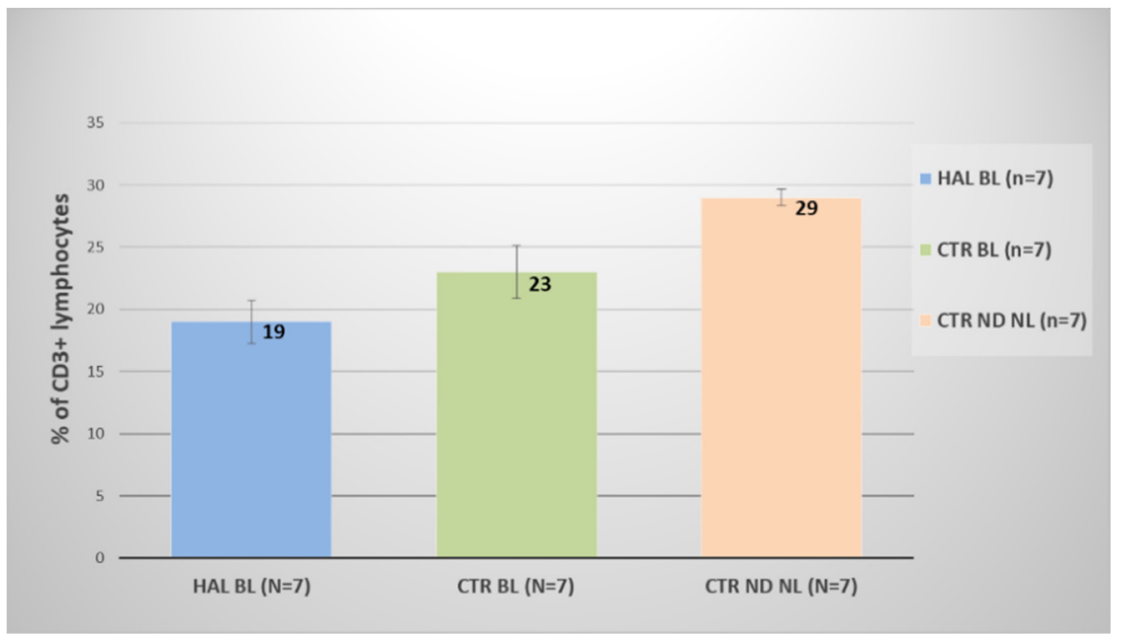

Figure 4. Expression of CD3+ lymphocytes in rat bladder tumors 30 days after tumor grafting in control and experimental groups.

Albeit no quantitative difference was observed in the expression of CD3+ after HAL BL compared to BL only, close examination of the slides revealed a different localization of the CD3+ lymphocytes. A strong CD3+ localization around tumor cells was observed in the HAL BL group, whereas in the CTR BL group, CD3+ lymphocytes were mostly localized on the periphery of tumor sample (Figure 5a,b). The same distribution pattern was observed for CD8+ lymphocytes (Figure 5c,d), but unlike CD3+ cells, partial localization was also seen in the control BL group. CD4+ cells were distributed on the periphery in both experimental groups (data not shown). Periphery localization of CD3+, CD4+ and CD8+ was also observed for untreated control tumors (data not shown). The localization of CD3+ and CD8+ lymphocytes around tumor cells in HAL BL-treated rat bladders could indicate a stimulation of the immune system explaining the anti-tumor effect (Table 2). Therefore, in the next step we studied whether the anti-tumor effect could be improved by combining exposure of HAL and BL with anti-PD-L1 immunotherapy.

(a)

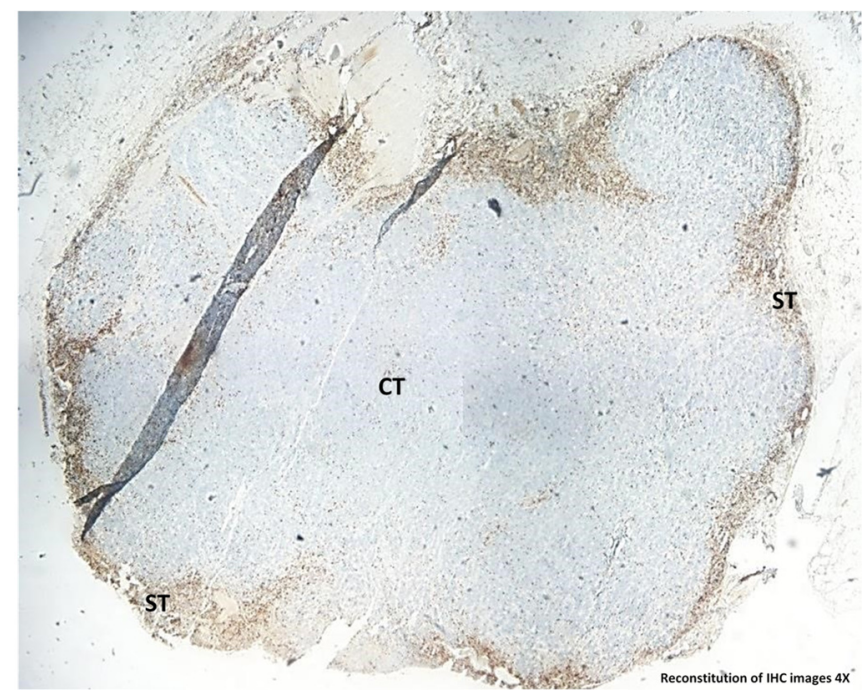

Figure 5. Cont. 
(b)

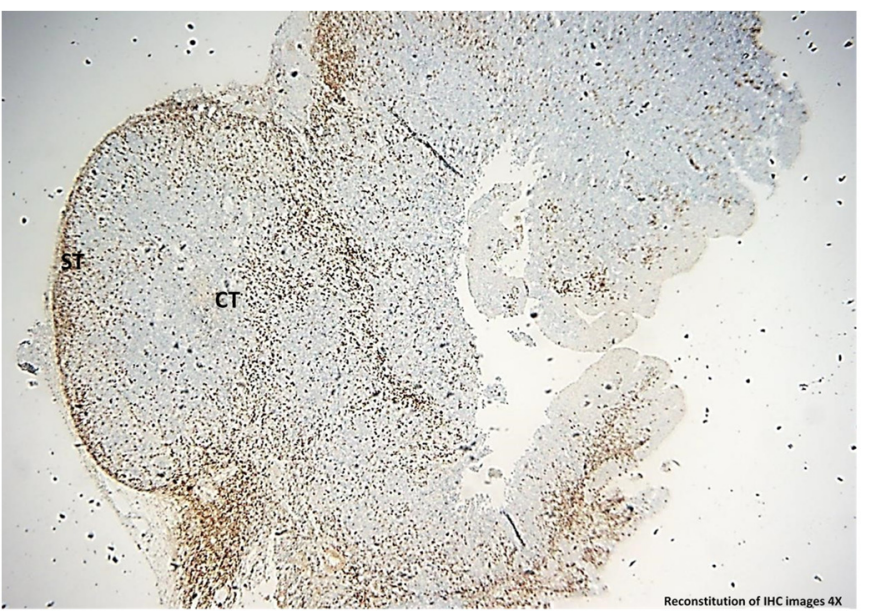

(c)

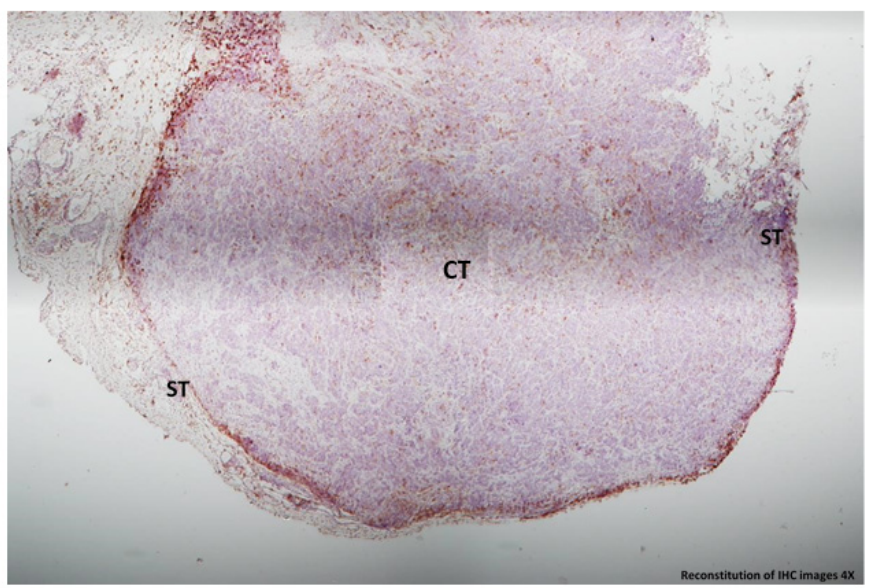

(d)

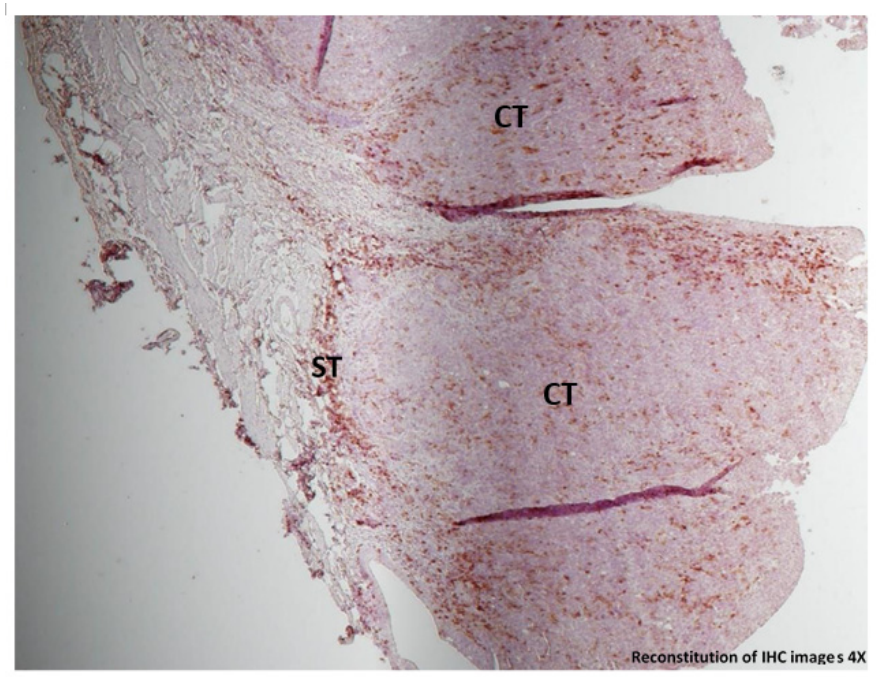

Figure 5. Typical images of CD3+ lymphocytes $(\mathbf{a}, \mathbf{b})$ and CD8+ lymphocytes $(\mathbf{c}, \mathbf{d})$ in bladder tumors 30 days post-grafting. (a) CD3+ lymphocytes in CTR BL sample displaying peripheral localization in stroma regions $(\mathrm{ST})(\times 4)$; (b) CD3+ lymphocytes in HAL BL sample displaying localization around tumor cells in the center of tumor (CT) $(\times 4)$; (c) CD8+ lymphocytes in CTR BL sample displaying peripheral localization in stroma regions (ST) $(\times 10)$; (d) CD8+ lymphocytes in HAL BL sample displaying localization around tumor cells in the center of tumor $(\mathrm{CT})(\times 10)$. 


\subsection{IHC-Assessed PD-L1 Expression in Bladder Tumor Cells}

PD-L1 expression was assessed in tumor cells collected from rats exposed to HAL BL, BL only and untreated control tumor at 7 days, 12 days, and 30 days after tumor grafting (Table 3). Only weak/moderate expression of PD-L1 was seen in the HAL BL and CTR BL groups at 7 days after tumor grafting (Table 3). Twelve days after tumor grafting, a transient increase to strong PD-L1 expression was observed in all experimental groups (Table 3; Figure 3a) but did not sustain. Indeed, 30 days after tumor grafting the PD-L1 expression returned back to weak/moderate levels (Table 3; Figure 3b,c).

Table 3. IHC-assessed PD-L1 expression at 7, 12, and 30 days after tumor inoculation in control (CTR ND NL, CTR BL) and HAL BL-treated bladder tumors.

\begin{tabular}{|c|c|c|c|c|}
\hline $\begin{array}{l}\text { Time after Grafting } \\
\text { (Days) }\end{array}$ & Treatments & $\begin{array}{c}50<\text { PD-L1 }<100 \% \\
\text { Strong }\end{array}$ & $\begin{array}{c}1<\text { PD-L1 }<49 \% \\
\text { Moderate }\end{array}$ & PD-L1 < 1\% Weak \\
\hline 7 & $\begin{array}{l}\text { HAL BL } \\
(\mathrm{n}=4)\end{array}$ & $0 / 4$ & $1 / 4$ & $3 / 4$ \\
\hline \multirow{3}{*}{12} & $\begin{array}{l}\text { CTR ND NL } \\
\quad(\mathrm{n}=4)\end{array}$ & $3 / 4$ & $1 / 4$ & $0 / 4$ \\
\hline & $\begin{array}{l}\text { CTR BL } \\
(\mathrm{n}=4)\end{array}$ & $3 / 4$ & $1 / 4$ & $0 / 4$ \\
\hline & HAL BL $(n=6)$ & $4 / 6$ & $0 / 6$ & $2 / 6$ \\
\hline \multirow{3}{*}{30} & CTR ND NL $(\mathrm{n}=11)$ & $2 / 11$ & $1 / 11$ & $8 / 11$ \\
\hline & CTR BL $(\mathrm{n}=5)$ & $2 / 5$ & $2 / 5$ & $1 / 5$ \\
\hline & HAL BL $(\mathrm{n}=12)$ & $0 / 12$ & $1 / 12$ & $11 / 12$ \\
\hline
\end{tabular}

\subsection{Therapeutic Effect of Immune Checkpoint Therapy in AY27 Orthotopic Bladder Tumors}

The increased PD-L1 expression 12 days after tumor grafting justified further experiments with anti-PD-L1 immunotherapy. Two different administration routes of anti-PD-L1 were performed: intravesical (ives) and intraperitoneal (i.p.) and two different dosing regimens (Figure 1). No anti-tumor effect was observed in the controls treated with anti-PD-L1 ives or i.p. alone 30 days after tumor grafting (Table 4). However, all groups exposed to HAL showed a positive anti-tumor effect. This effect was significant for rats exposed to HAL BL alone and in combination with anti-PDL-1 immunotherapy compared with control groups $(p<0.05)$. A treatment regime with intravesical co-administration of HAL BL and anti-PD-L1 seemed to be more advantageous ( $38 \%$ ) compared to the other groups, although the difference was not statistically significant $(p>0.05)$ (Table 4$)$. It is important to note that no signs of suffering were noted with the combination with checkpoints inhibitors.

Table 4. HES-assessed anti-tumor effect in rat bladders 30 days after tumor inoculation. Tumor bearing rats were subjected to ives (intravesical) or i.p. (intraperitoneal) anti- PD-L1 immunotherapy.

\begin{tabular}{ccccccc}
\hline \multirow{2}{*}{ Treatments } & \multicolumn{3}{c}{ Tumor Response Grades } \\
\cline { 2 - 7 } & NR & MR & Near CR & CR & \multicolumn{2}{c}{ Near CR + CR } \\
\hline CTR PDL1 ives $(\mathrm{n}=9)$ & $9 / 9$ & $0 / 9$ & $0 / 9$ & $0 / 9$ & $0 / 9$ & $0 \%$ \\
\hline CTR PDL1 i.p $(\mathrm{n}=10)$ & $10 / 10$ & $0 / 10$ & $0 / 10$ & $0 / 10$ & $0 / 10$ & $0 \%$ \\
\hline HAL BL PDL1 i.p $(\mathrm{n}=9)$ & $7 / 9$ & $0 / 9$ & $1 / 9$ & $1 / 9$ & $2 / 9$ & $3 / 10$ \\
\hline HAL BL PDL1 ives $(\mathrm{n}=10)$ & $6 / 10$ & $1 / 10$ & $0 / 10$ & $3 / 10$ & $3 / 8$ & $38 \%$ \\
\hline $\begin{array}{c}\text { HAL BL PD-L1 ives } \\
\text { Co-administered }(\mathrm{n}=8)\end{array}$ & $3 / 8$ & $2 / 8$ & $2 / 8$ & $1 / 8$ & $31 \%$ \\
\hline HAL BL * $(\mathrm{n}=13)$ & $8 / 13$ & $1 / 13$ & $0 / 13$ & $4 / 13$ & $4 / 13$ & $31 \%$ \\
\hline
\end{tabular}

HAL BL: HAL and blue light, CTR: control no drug no light, NR: no response, MR; moderate response, CR complete response. ${ }^{*}$ Taken from Table 2 . 


\section{Discussion}

In our study, we used blue light illumination after intravesical instillation of hexylaminolevulinate alone and in combination with checkpoint inhibitor in rat bladders with orthotopic tumors. This tumor model mimics bladder cancer in humans standing mostly for NMIBC, with a progression to MIBC (stages II-III) [26,32,33]. Studies of photodynamic therapy (PDT) with HAL and red light has been performed in this orthotopic bladder cancer model, demonstrating a positive short-term ( $48 \mathrm{~h}-168 \mathrm{~h})$ therapeutic effect $[34,35]$. Therefore, this model should be suitable for our experiments.

In terms of dosimetry, the idea was to mimic the light doses used during a clinical blue light cystoscopy (PhotoDynamic Diagnosis, PDD). Based on measurements of blue light intensity from the tip of the cystoscope, the average range of light intensities was calculated at the distance between the scope and tumor during a PDD bladder investigation assuming a working distance between 3 and $5 \mathrm{~cm}$. Furthermore, the age of the lamp was considered since its intensity varies with lamp age between $100-60 \%$ (lower limit) of full intensity. Based on the above, a range of irradiances of $1.8-12.3 \mathrm{~mW} / \mathrm{cm}^{2}\left(\right.$ mean $\left.7.0 \mathrm{~mW} / \mathrm{cm}^{2}\right)$ was obtained. In our case, the delivered light doses were calculated by multiplying the above range with the range of typical blue light exposure times during tumor-resection (2-20 $\mathrm{min}$ ) yielding a range of light doses of $0.2-14.8 \mathrm{~J} / \mathrm{cm}^{2}$ (mean $\left.7.5 \mathrm{~J} / \mathrm{cm}^{2}\right)$. Precise light dosing in in vivo studies, especially in hollow organs, is difficult to conduct due to variations in multiply parameters e.g., light diffusion, light scattering, and exact tumor localization. Therefore, certain caution is needed while interpreting the results. Based on these calculations, we used a fixed irradiance at $7 \mathrm{~mW} / \mathrm{cm}^{2}$ and a total light dose of $7.5 \mathrm{~J} / \mathrm{cm}^{2}$. This is in the same range as documented by Karl Storz for their D-Light C Photodynamic Diagnosis (PDD) system [27]. They report irradiance of blue light $\left(\mathrm{mW} / \mathrm{cm}^{2}\right)$ of $1.3,3.5$, and 32 for distances from tissue of 5,3 , and $1 \mathrm{~cm}$, respectively.

In this study, we found a significant anti-tumor effect at observation end point, which was fixed at 30 days after tumor grafting with complete response (CR) in 31\% (4/13 rats) of animals exposed to HAL and BL (Table 2). At the same time, we observed a strong tumor infiltration with CD3+ and CD8+ T cells in this experimental group indicating a T cellmediated immune response. Enhancement of $\mathrm{T}$ cell activation has also been reported in studies of HAL red light PDT in a similar orthotopic bladder cancer model in rats [32]. The $\mathrm{T}$ cells infiltration is a result of an alteration in the tumor microenvironment, stimulating the release of different mediators and recruiting lymphocytes from the circulating blood to the tumor [36,37]. It appears that exposure of HAL BL as used during a diagnostic PDD procedure may result in a similar immune stimulation with activating of the innate and adaptive pathways $[9,11,12]$. It is likely that this immune system activation is the reason for the anti-tumor effect in the rats exposed to HAL and BL. A higher proportion of rats showed an anti-tumor effect 12 days after being exposed to HAL BL. At this time point, $63 \%$ of the rats showed CR (2/8 rats) or near CR (3/8) (Table 2). During the time period between 12 and 30 days, $\mathrm{T}$ cell dysfunction, exhaustion, and tolerance may happen due to the ligation of PD-1 with PD-L1 ligand, thus contributing to diminishing of HAL BL long-term effect. PD-1 or PD-L1 blockade can lead to an enhancement of anti-tumor activity [20]. It is also possible that the immune stimulation following single exposure to HAL and BL is not strong enough to control the tumor growth in this model. With the aim of achieving a sustained anti-tumor effect and to assess whether there could be an additional treatment effect we applied a combination of HAL and BL with targeted antiPD-1 immunotherapy. PD-L1 is strongly expressed in MIBC but also in advanced stages of NMIBC [28]. Two administration routes of anti-PD-1 were tested in this model, intravesical and intraperitoneal. Irrespective of intravesical or intraperitoneal administration, targeted immunotherapy administered alone was ineffective as none of the tested rats responded positively (Table 4). Contrary, all groups exposed to HAL showed a positive anti-tumor effect although this effect was statistically significant only for rats exposed to HAL BL and where HAL BL was combined with intravesical administered anti-PDL-1 immunonotherapy. A treatment regime where HAL BL and anti-PD-L1 were co-administered intravesically at 
the same day provided the best antitumor effect where $38 \%$ of the rats showed near CR and CR. The somewhat lower anti-tumor effect when anti-PD-1 was administered i.p. (22\%) compared to ives (30\%) might also be explained by the lower concentration of anti-PD-1 used for this administration route.

The rather modest incremental effect seen when combining HAL BL with anti-PD1 might be explained by the weak PD-L1 expression on the tumor cells. In our study, IHC-assessed PD-L1 expression in bladder cancer samples clearly showed that a strong expression of PD-L1 was evident 12 days after tumor implantation but it did not sustain (Table 3). Although expression of PD-L1 in tumors is correlated with higher response to therapy, this is not definite, and it is argued that an absence of PD-L1 expression in biopsies does not preclude response to anti-PD-1/PD-L1 immunotherapy [22]. It has earlier been reported that radiotherapy upregulates the PD-L1 expression on tumors cells, justifying the combination with anti-PD1/anti-PD-L1 inhibitors [28]. Moreover, CD8+ T cells are shown to be vital for the local and systemic therapeutic effects seen after combining radiation with checkpoint inhibitors [28]. As tumor infiltration with CD8+ T cells was not observed in our study until 30 days after tumor grafting, a potential upregulation of the PD-L1 expression as a consequence of $\mathrm{T}$ cell tumor infiltration amplifying the effect of the anti-PD-1 checkpoint inhibitor was not possible to rule out at observation end point for our study.

A recent study of Kirschner et al. compared efficacy of intravesical versus systemic (intraperitoneal) administration of an anti-PD-1 inhibitor in the treatment of localized bladder cancer in an orthotopic mouse model [38]. Intravesical anti-PD-1 administration had trend to improved survival thus providing effective anti-tumor treatment for bladder tumors. Further, increased CD8+ T cells infiltration in tumors was observed, especially after intravesical administration. Our study also demonstrated that intravesical administration of anti-PD-L1 combined with HAL BL has an improved survival over systemic i.p. administration, probably due to a higher local drug concentration after ives administration. Local immunotherapy administration into the bladder could represent a substantial clinical benefit, reducing systemic exposure and side effects. Our study in rats and the study reported by Kirschner et al. [38] in mice are encouraging in this respect. However, additional clinical trials are warranted before intravesical instillation of anti-PD-L1 could be widely used in humans alone or in combination with HAL and BL.

This is to the best of our knowledge the first proof-of principle study demonstrating an anti-tumor effect and indication of immune activation following HAL and BL exposure in vivo. Our hypothesis of immune activation could be strengthened by performing $\mathrm{T}$ cell depletion using anti-CD3. Moreover, IHC assessments could be supplemented by flow cytometry to give more conclusive results. Future studies can benefit from analysis of other immune markers including cytokine panels, antigen-specific CD8+, and granzyme B production.

\section{Conclusions}

We have demonstrated an anti-tumor effect of HAL and blue light when trying to mimic the dosing regimen of a photodynamic diagnostic procedure in an orthotropic bladder cancer model in rats. The anti-tumor effect is most probably pertaining to stimulation of the immune system as evident by tumor infiltration of CD3+ and CD8 + T cells. These results support our hypothesis that the positive impact on patient outcomes observed in patients who had undergone BLC prior to cystectomy could be explained by systemic immune activation induced by HAL and blue light. Combination of HAL and blue light with intravesical anti-PD-L1 resulted in increased anti-tumor effects. Further studies are warranted to explore the long-term effects of HAL and blue light alone or in combination with checkpoint inhibitors which should extend to investigate any systemic (abscopal) effects. The idea that local treatment with HAL and blue light can prime an immune response with potential additional effect of checkpoint inhibitors is also intriguing. 


\begin{abstract}
Author Contributions: Investigation, methodology, L.L.; formal analysis, validation, J.T.; formal analysis, investigation, A.L.; methodology, supervision, J.-F.B.; Writing-review and editing, K.M.; Conceptualization, project administration, writing—original draft, A.G.; funding acquisition, Methodology, writing — original draft, writing — review and editing, G.S.; project administration, supervision, writing-original draft, writing - review and editing, L.B. All authors have read and agreed to the published version of the manuscript.
\end{abstract}

Funding: This work was supported by Photocure ASA (Oslo, Norway) which also supplied Hexvix ${ }^{\circledR}$. Aslak Godal, Gry Stensrud and Kari Myren were employed by Photocure ASA during the course of this study.

Institutional Review Board Statement: The study was conducted according to the guidelines of the European Communities Council Directive on the approximation of laws, regulations, and administrative provisions of the Member States regarding the protection of animals used for scientific purposes, the National Institutes of Health Guide for the care and use of laboratory animals and the ASAB Ethical Committee. The studies received approval from the French Ministry of Higher Education and Research (agreements no. APAFIS\#14510 on 9 July 2018, and no. APAFIS\#23597 on 3 March 2020).

Data Availability Statement: The dataset generated and analyzed in this study is not publicly available but may be obtained from the corresponding author upon reasonable request.

Acknowledgments: The authors thank Knut Dyrstad, KD Metrix, for his expertise and assistance with the statistical analysis used in this manuscript.

Conflicts of Interest: The authors declare no conflict of interest.

\title{
References
}

1. Miranda-Filho, A.; Bray, F.; Charvat, H.; Rajaraman, S.; Soerjomataram, I. The world cancer patient population (WCPP): An updated standard for international comparisons of population-based survival. Cancer Epidemiol. 2020, 69, 101802. [CrossRef] [PubMed]

2. Matulewicz, R.S.; Steinberg, G.D. Non-muscle-invasive bladder cancer: Overview and contemporary treatment landscape of neoadjuvant chemoablative therapies. Rev. Urol. 2020, 22, 43-51. [PubMed]

3. Di Stasi, S.M.; De Carlo, F.; Pagliarulo, V.; Masedu, F.; Verri, C.; Celestino, F.; Riedl, C. Hexaminolevulinate hydrochloride in the detection of nonmuscle invasive cancer of the bladder. Ther. Adv. Urol. 2015, 7, 339-350. [CrossRef] [PubMed]

4. Stenzl, A.; Burger, M.; Fradet, Y.; Mynderse, L.A.; Soloway, M.S.; Witjes, J.A.; Kriegmair, M.; Karl, A.; Shen, Y.; Grossman, H.B. Hexaminolevulinate guided fluorescence cystoscopy reduces recurrence in patients with nonmuscle invasive bladder cancer. $J$. Urol. 2010, 184, 1907-1914. [CrossRef] [PubMed]

5. Grossman, H.B.; Stenzl, A.; Fradet, Y.; Mynderse, L.A.; Kriegmair, M.; Witjes, J.A.; Soloway, M.S.; Karl, A.; Burger, M. Long-term decrease in bladder cancer recurrence with hexaminolevulinate enabled fluorescence cystoscopy. J. Urol. 2012, $188,58-62$. [CrossRef]

6. Chang, S.S.; Boorjian, S.A.; Chou, R.; Clark, P.E.; Daneshmand, S.; Konety, B.R.; Pruthi, R.; Quale, D.Z.; Ritch, C.R.; Seigne, J.D.; et al. Diagnosis and treatment of non-muscle invasive bladder cancer: AUA/SUO guideline. J. Urol. 2016, 196, 1021-1029. [CrossRef]

7. EAU Guidelines: Non-Muscle-Invasive Bladder Cancer. Available online: https://uroweb.org/guideline/non-muscle-invasivebladder-cancer/ (accessed on 5 January 2022).

8. Garg, A.D.; Nowis, D.; Golab, J.; Agostinis, P. Photodynamic therapy: Illuminating the road from cell death towards anti-tumour immunity. Apoptosis 2010, 15, 1050-1071. [CrossRef]

9. Mroz, P.; Hashmi, J.T.; Huang, Y.; Lange, N.; Hamblin, M.R. Stimulation of anti-tumor immunity by photodynamic therapy. Expert Rev. Clin. Immunol. 2011, 7, 75-91. [CrossRef]

10. Reginato, E.; Wolf, P.; Hamblin, M.R. Immune response after photodynamic therapy increases anti-cancer and anti-bacterial effects. World J. Immunol. 2014, 4, 1-11. [CrossRef]

11. Anzengruber, F.; Avci, P.; de Freitas, L.F.; Hamblin, M.R. T-cell mediated anti-tumor immunity after photodynamic therapy: Why does it not always work and how can we improve it? Photochem. Photobiol. Sci. 2015, 14, 1492-1509. [CrossRef]

12. Hwang, H.S.; Shin, H.; Han, J.; Na, K. Combination of photodynamic therapy (PDT) and anti-tumor immunity in cancer therapy J. Pharm. Investig. 2018, 48, 143-151. [CrossRef] [PubMed]

13. Bader, M.J.; Stepp, H.; Beyer, W.; Pongratz, T.; Sroka, R.; Kriegmair, M.; Dirk, Z.; Mona, W.; Derya, T.; Christian, G.S.; et al. Photodynamic therapy of bladder cancer-A phase I study using hexaminolevulinate (HAL). Urol. Oncol. Semin. Orig. Investig. 2013, 31, 1178-1183. [CrossRef] [PubMed]

14. Gakis, G.; Ngamsri, T.; Rausch, S.; Mischinger, J.; Todenhöfer, T.; Schwentner, C.; Schmid, M.A.; Hassan, F.A.-S.; Renninger, M.; Stenzl, A. Fluorescence-guided bladder tumour resection: Impact on survival after radical cystectomy. World J. Urol. 2015, 33, 1429-1437. [CrossRef] [PubMed] 
15. Renninger, M.; Fahmy, O.; Schubert, T.; Schmid, M.A.; Hassan, F.; Stenzl, A.; Gakis, G. The prognostic impact of hexaminolevulinate-based bladder tumor resection in patients with primary non-muscle invasive bladder cancer treated with radical cystectomy. World J. Urol. 2019, 38, 397-406. [CrossRef] [PubMed]

16. Pardoll, D.M. The blockade of immune checkpoints in cancer immunotherapy. Nat. Rev. Cancer 2012, 12, 252-264. [CrossRef]

17. Song, D.; Powles, T.; Shi, L.; Zhang, L.; Ingersoll, M.A.; Lu, Y. Bladder cancer, a unique model to understand cancer immunity and develop immunotherapy approaches. J. Pathol. 2019, 249, 151-165. [CrossRef]

18. Kim, H.S.; Seo, H.K. Emerging treatments for bacillus Calmette-Guérin-unresponsive non-muscle-invasive bladder cancer. Investig. Clin. Urol. 2021, 62, 361-377. [CrossRef]

19. Lopez-Beltran, A.; Cimadamore, A.; Blanca, A.; Massari, F.; Vau, N.; Scarpelli, M.; Cheng, L.; Montironi, R. Immune checkpoint inhibitors for the treatment of bladder cancer. Cancers 2021, 13, 131. [CrossRef]

20. Hahn, N.M.; Necchi, A.; Loriot, Y.; Powles, T.; Plimack, E.R.; Sonpavde, G.; Roupret, M.; Kamat, A.M. Role of checkpoint inhibition in localized bladder cancer. Eur. Urol. Oncol. 2018, 1, 190-198. [CrossRef]

21. Anand, S.; Chan, T.; Hasan, T.; Maytin, E. Current prospects for treatment of solid tumors via photodynamic, photothermal, or ionizing radiation therapies combined with immune checkpoint inhibition (a review). Pharmaceuticals 2021, 14, 447. [CrossRef]

22. O’Shaughnessy, M.J.; Murray, K.S.; La Rosa, S.P.; Budhu, S.; Merghoub, T.; Somma, A.; Monette, S.; Kim, K.; Corradi, R.B.; Scherz, A.; et al. Systemic antitumor immunity by PD-1/PD-L1 inhibition is potentiated by vascular-targeted photodynamic therapy of primary tumors. Clin. Cancer Res. 2017, 24, 592-599. [CrossRef] [PubMed]

23. Gao, L.; Zhang, C.; Gao, D.; Liu, H.; Yu, X.; Lai, J.; Wang, F.; Lin, J.; Liu, Z. Enhanced anti-tumor efficacy through a combination of integrin $\alpha \mathrm{v} \beta 6$-targeted photodynamic therapy and immune checkpoint inhibition. Theranostics 2016, 6, 627-637. [CrossRef] [PubMed]

24. Kleinovink, J.W.; Fransen, M.F.; Löwik, C.W.; Ossendorp, F. Photodynamic-Immune checkpoint therapy eradicates local and distant tumors by CD8+ T cells. Cancer Immunol. Res. 2017, 5, 832-838. [CrossRef]

25. Liu, Q.; Tian, J.; Tian, Y.; Sun, Q.; Sun, D.; Wang, F.; Xu, H.; Ying, G.; Wang, J.; Yetisen, A.K.; et al. Near-infrared-ii nanoparticles for cancer imaging of immune checkpoint programmed death-ligand 1 and photodynamic/immune therapy. ACS Nano 2021, 15, 515-525. [CrossRef] [PubMed]

26. Xiao, Z.; McCallum, T.J.; Brown, K.M.; Miller, G.G.; Halls, S.B.; Parney, I.; Moore, R. Characterization of a novel transplantable orthotopic rat bladder transitional cell tumour model. Br. J. Cancer 1999, 81, 638-646. [CrossRef] [PubMed]

27. Summary of Safety and Effectiveness (SSED). Karl Storz D-Light C Photodynamic Diagnosis (PDD) System. PMA Number P050027. Available online: https:/ / fda.report/PMA/P050027/5/P050027B.pdf (accessed on 9 February 2022).

28. Wu, C.-T.; Chen, W.-C.; Chang, Y.-H.; Lin, W.-Y.; Chen, M.-F. The role of PD-L1 in the radiation response and clinical outcome for bladder cancer. Sci. Rep. 2016, 6, 19740. [CrossRef] [PubMed]

29. Efficacy of Durvalumab in Non-Muscle-Invasive Bladder Cancer. Available online: https://www.clinicaltrials.gov / ct2/show / NCT03759496?term=PD-L1\&cond=NMIBC\&rank=1 (accessed on 7 February 2022).

30. Kim, S.H.; Chan, P.S.; Kim, D.Y.; Park, J.W.; Baek, J.Y.; Kim, S.Y.; Park, S.C.; Oh, J.H.; Byung-Ho, N.; Nam, B.-H. What is the ideal tumor regression grading system in rectal cancer patients after preoperative chemoradiotherapy? Cancer Res. Treat. 2016, 48 , 998-1009. [CrossRef]

31. Bressenot, A.; Marchal, S.; Bezdetnaya, L.; Garrier, J.; Guillemin, F.; Plénat, F. Assessment of apoptosis by immunohistochemistry to active caspase-3, active caspase-7, or cleaved PARP in monolayer cells and spheroid and subcutaneous xenografts of human carcinoma. J. Histochem. Cytochem. 2009, 57, 289-300. [CrossRef]

32. Arum, C.-J.; Gederaas, O.A.; Larsen, E.L.P.; Randeberg, L.L.; Hjelde, A.; Krokan, H.E.; Svaasand, L.O.; Chen, D.; Zhao, C.-M Tissue responses to hexyl 5-aminolevulinate-induced photodynamic treatment in syngeneic orthotopic rat bladder cancer model: Possible pathways of action. J. Biomed. Opt. 2011, 16, 028001. [CrossRef]

33. Lilge, L.; Roufaiel, M.; Lazic, S.; Kaspler, P.; Munegowda, M.A.; Nitz, M.; Bassan, J.; Mandel, A. Evaluation of a Ruthenium coordination complex as photosensitizer for PDT of bladder cancer: Cellular response, tissue selectivity and in vivo response. Transl. Biophotonics 2020, 2, 2. [CrossRef]

34. Larsen, E.L.P.; Randeberg, L.L.; Gederaas, O.A.; Arum, C.-J.; Hjelde, A.; Zhao, C.-M.; Chen, D.; Krokan, H.E.; Svaasand, L.O. Monitoring of hexyl 5-aminolevulinate-induced photodynamic therapy in rat bladder cancer by optical spectroscopy. J. Biomed. Opt. 2008, 13, 044031. [CrossRef] [PubMed]

35. François, A.; Salvadori, A.; Bressenot, A.; Bezdetnaya, L.; Guillemin, F.; D'Hallewin, M.A. How to avoid local side effects of bladder photodynamic therapy: Impact of the fluence rate. J. Urol. 2013, 190, 731-736. [CrossRef] [PubMed]

36. Rocha, L.B.; Gomes-Da-Silva, L.C.; Dabrowski, J.M.; Arnaut, L.G. Elimination of primary tumours and control of metastasis with rationally designed bacteriochlorin photodynamic therapy regimens. Eur. J. Cancer 2015, 51, 1822-1830. [CrossRef] [PubMed]

37. Preise, D.; Oren, R.; Glinert, I.; Kalchenko, V.; Jung, S.; Scherz, A.; Salomon, Y. Systemic antitumor protection by vascular-targeted photodynamic therapy involves cellular and humoral immunity. Cancer Immunol. Immunother. 2009, 58, 71-84. [CrossRef]

38. Kirschner, A.N.; Wang, J.; Rajkumar-Calkins, A.; Neuzil, K.E.; Chang, S.S. Intravesical anti-pd-1 immune checkpoint inhibition treats urothelial bladder cancer in a mouse model. J. Urol. 2020, 205, 1336-1343. [CrossRef] 